\title{
A REVIEW ON SOFTWARE-DEFINED NETWORKING ENABLED IOT CLOUD COMPUTING
}

\author{
SUMit BAdotra, Surya Narayan PANDA \\ Chitkara University Institute of Engineering and Technology, \\ Chitkara University, Punjab, India. \\ *Corresponding author: sumit.badotra@chitkara.edu.in
}

(Received: $8^{\text {th }}$ April 2019; Accepted: 24 th July 2019; Published on-line:2 $2^{\text {nd }}$ December 2019)

\begin{abstract}
Making use of Internet of Things (IoT) is becoming the necessity of today's life. The data collected and stored through IoT devices comes from the cloud and therefore cloud computing is acting as a backbone for supporting IoT. But it is easy to forget that the cloud is not completely digital in some areas of the world and there is a need for a data centre where data storage can be achieved. Cloud data centres are facing many difficulties and issues because they are using traditional methods of networking. This is where Software Defined Networking (SDN) has come into view; where it has changed the way traditional networks are operated. For example, the separation of the intelligence of the network devices within the data path can be useful in making networks agile and manageable. This paper aims to provide problem areas in the networking used by the cloud data centres and the role of SDN to overcome these issues. Platforms for providing the experimental setup for collaboration between SDN and cloud will ultimately be beneficial in setting up the SDN- enabled IoT cloud, and this is also discussed with the open research problems.
\end{abstract}

ABSTRAK: Penggunaan Internet Benda (IoT) menjadi keperluan kepada kehendak hari ini. Data yang dikumpul dan disimpan melalui peranti IoT berasal dari awan dan oleh itu pengkomputeran awan bertindak sebagai tulang belakang bagi menyokong IoT. Tetapi, satu perkara yang dilupakan adalah bahawa awan itu tidak sepenuhnya digital, di suatu tempat dalam dunia ini, terdapat keperluan pada pusat data di mana penyimpanan data boleh dicapai. Pusat data awan menghadapi banyak masalah dan isu kerana ianya menggunakan kaedah rangkaian tradisional. Di sinilah Perisian Definisi Perangkaian (SDN) dipandang; ia telah mengubah cara rangkaian tradisional dikendalikan. Sebagai contoh, pemisahan kecerdasan peranti rangkaian dengan laluan data berguna bagi membuat rangkaian pintar dan boleh diurus. Kajian ini bertujuan bagi menyediakan ruang masalah dalam rangkaian yang digunakan oleh pusat Data Awan dan peranan SDN dalam mengatasi masalah ini. Platform persediaan eksperimen bagi kerjasama SDN dan awan akhirnya bermanfaat dalam menubuhkan pengaktifan-SDN awan IOT, juga turut dibincangkan dalam kajian ini berkenaan masalah penyelidikan terbuka.

KEYWORDS: internet of things (IoT); software defined networking (SDN); data center networks; cloud computing

\section{INTRODUCTION}

Internet of things (IoT) and cloud computing are strongly related to each other. Data transferred to various IoT devices comes from data centres. IoT is not all about how to connect various devices to the Internet to get the information but how to analyse the data 
to get an intelligent answer to a query. Analysis of the data can only be possible if it is being stored at a data centre. Then, the IoT device can make a decision based on a previous data decision. For example, a smart watch is not only smart because it is connected to the Internet but because it is making use of some cloud where the data is stored, and analysing that cumulative data and making a smart decision. Cloud computing has emerged in such a simple way that its acceptance is universal. The computing that has been facilitated by cloud computing has eliminated several problems while providing services to the shoppers like direct investment, minimizing operational expenses, the handiness of on-request computing resources, protractible scaling, and creating pay-peruse [1]. As the utility of this computing model is expanding, it should be matched with a supplier of cloud with a similar brokering system that is dynamic for hosting its application [1]. The application supplier can lease resources used for computing from the cloud supplier by just clicking on a mouse at regular intervals and using their application without direct payment. With a dynamic adjustment (either increasing or decreasing) of the amount of virtualized infrastructure resources such as virtual machines (VMs), the extensibility and flexibility in the cloud atmosphere is achieved [2].

To give versatile support of their shoppers, cloud suppliers work with varied information centres over totally different locations with virtualized quality provisioning. Substantial giant information centres are comprised of thousands of switches interfacing unnumbered servers [3]. Each server will serve varied application demands from varied shoppers by utilizing virtualization advances that have improved readiness and asset capability that were not previously in the network resources [3]. As of now, cloud shoppers will lease virtualized process assets, i.e., VMs (virtual machines), and virtualized storage from different cloud suppliers that are allotted for the shopper. Be that as it may, the system quality virtualization innovation remains an extended method being employed within business public clouds [4].

Servers are allotted to totally different customers if the mass or total requested size from shoppers doesn't exceed server limit. Cloud shoppers accept inquiring for some littler measured resources than the limit of the entire server, and a server will offer varied virtual machines [5]. These virtual machines connect to the customer through varied system switches and switches. So as to transfer the traffic among varied VMs effectively and with information efficiency, network centres are established. Because the Data Centre Network (DCN) interfaces a huge range of servers, the system can have better quality, which makes it exhausting to administrate and scale within the standard systems administration view. In customary systems, every system switch has its own specific management explanation that solely chooses its conduct based on the info obtained from its neighbours [6]. The traditional system approach is wasteful with regards to the information centre of the cloud, where a better thickness provided by varied virtual machine servers that increasingly change over time $[5,6]$.

In order to overcome the disadvantages of traditional networks like measurability problems, inflexibility, etc. [7] different cloud information centres have started accepting the software-defined networking (SDN) thought in their DCNs [7, 8]. With the help of SDN, provisioning of incorporated centralized management logic with a perspective of the full system at the centralized controller will form dynamic changes on the conduct of the system $[9,10]$. The network will likewise be modified by the controller, which is well suited to the more dynamic nature of the service provided by the cloud [11, 12]. Large suppliers of clouds, Google for example, formally received the SDN plan in their information centres [13]. There is a tremendous rise in the rate of IoT devices and to accommodate the growth of this rate, the cloud data centre has to expand its functionality 
in order to provide the best services to every user. So, there is a need to implement the new architecture of cloud networking to enable innovation and continue the functionality and services of cloud.

In this paper, each cloud computing and SDN are considered for examination purposes. The main contribution of this paper is to explore the challenges and issues before and after introduction of SDN in IoT and cloud computing for future remedies. The remainder of this research paper is structured as follows:

In section II related literature is discussed along with the issues in the cloud data centre network with a brief introduction of SDN. In section III and IV comprehensive review of the state of art, including on-going projects and research, motivating SDN-Enabled IoT cloud computing is given. Section V is comprised of various evaluation methods that can be used as a platform for performing experiments in SDN-Enabled IoT cloud computing. Section VI explores the spectrum of challenges and obstacles in traditional networks, followed by concluding observations in section VII.

\section{BACKGROUND}

Although several surveys and taxonomies are conferred in SDN and cloud computing contexts, each of them presents their own drawbacks within the space. Toosi et al. [14] did a survey specializing in interconnected cloud computing. This research paper discussed various abilities in the context of multiple information centres and elaborately discussed every approach to work for cloud information centres that were interconnected. This paper had a separate section where it explained various networking challenges for inter-cloud connections, however, the main focus was on the broader problem of desegregation of multiple cloud information centres from the perspective of a cloud broker.

Mastelic et al. [15] additionally conferred a review on the potency of cloud energy for computing. In cloud computing, a scientific class of energy consumption has been instructed with respect to factors like software and hardware systems infrastructure in clouds. The author additionally discussed the networking aspect, accenting the information centre networking (DCN), end-user network, and inter-data-centre network. A detailed survey was done on various aspects of energy potency in networks, but the article was lacking with respect to the context of SDN.

Jararweh et al. [16] discussed in depth about software-defined clouds that specialized in networking, security, systems, and storage. However, his paper emphasized the system design instead of an individual analysis of SDN clouds.

Azodolmolky et al. [17] additionally proposed an innovative software-defined network. SDN can be applied to a number of challenges and will be utilized in future deployments as an economical solution along with cloud computing networking as a possible contributor of a software system outlined network. Some analysis results on the performance of the area unit are presented in this paper.

Yen et al. [18] initially established an association in Nursing SDN that is based on a cloud computing atmosphere via OpenFlow Switches, Controller packages, and Open supply. Then, it explained the practicality of the power saving OpenFlow controller to supply load equalization and observance mechanisms. To prove the feasibility of their planned design, they additionally developed a model of SDN queuing and estimated its analytical resolution for the chances of a steady-state. The result obtained from the experiment showed that the atmosphere based on SDN gave QoS-bonded services for cloud computing. 
Before starting an investigation of SDN-empowered cloud computing, the fundamentals of cloud computing are discussed and that's why the cloud information centres areas unit are represented. During the following section, we try to briefly discuss cloud computing, DCN, and SDN.

\subsection{Cloud Computing}

Cloud computing has come up as a typically acknowledged registering worldview worked around centre ideas [19], as an example, elimination of forthright venture, the diminishment of operational prices, on-request process resources, versatile scaling, and putting in compensation for every utilization arrange action for information innovation and computation administrations [20]. Cloud computing has given economy to ability through financially savvy and versatile IT profit worldview. The specialist additionally outfits its benefits, the pay-as-you-utilize estimating model for example, and flexibility to reinforce their nature of administration and to minimize their price [20]. In cloud condition, skill and flexibility will be accomplished by more decreasing or increasing virtualized foundation assets, e.g. VMs. In fact, virtualization had distended the efficiency and limit of cloud information centres to a degree that ancient system standards cannot offer [2122]. Figure 1 shows the varied features of cloud computing.

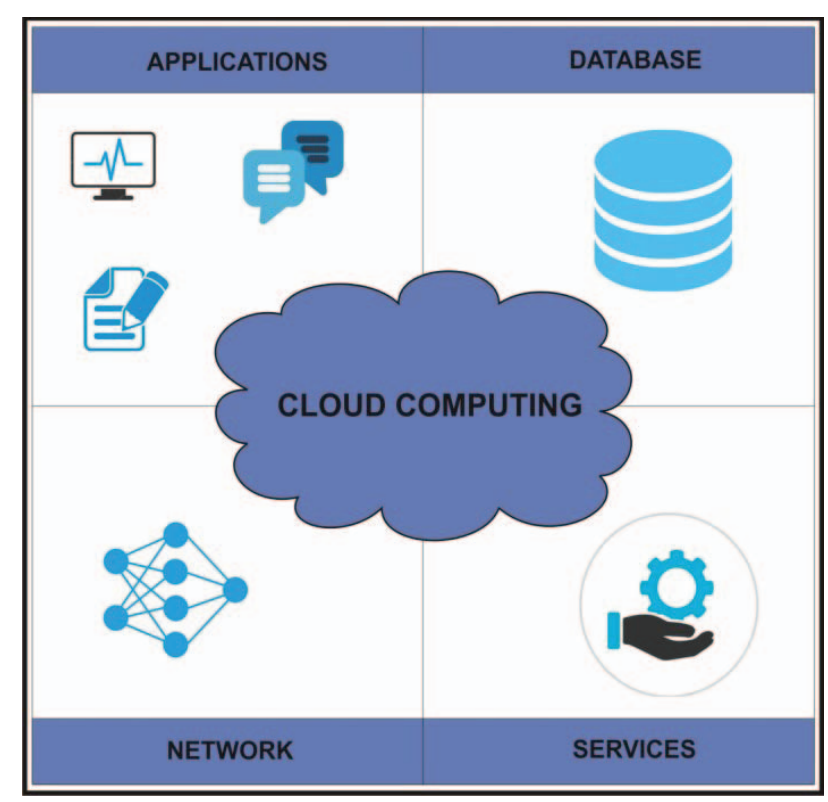

Fig. 1: Features of cloud computing.

The numerous service models of cloud computing enable varied administrations like Platform-as-a-service (PaaS), Software-as-a-Service (SaaS), Infrastructure-as-aService(IaaS), and Network-as-a-Service (NaaS) [23]. In SaaS, benefits for the outside provider has various applications that can later be made accessible to the shoppers online [24-25]. The NaaS profit model will incorporate elastic and broadened Virtual Private Network (VPN), transfer speed for the asking, custom steering, multicast conventions, security firewall, Intrusion Detection System, Wide Area Networking (WAN), content monitoring and separation, and antivirus [26-28]. There's no commonplace determination with respect to what's incorporated into NaaS and its executions can shift. Platform-as-aService (PaaS) may be a cloud computing model in which an outsider provider conveys instrumentation and programming devices for the main half to those needed for application advancement to shoppers over the web [29]. In PaaS, the supplier has the 
instrumentation and programming framework [30-33]. Thus, PaaS allows its shoppers to put in in-house instrumentation and programming to form or run another applications [34]. Figure 2 demonstrates the various administration models of cloud computing.

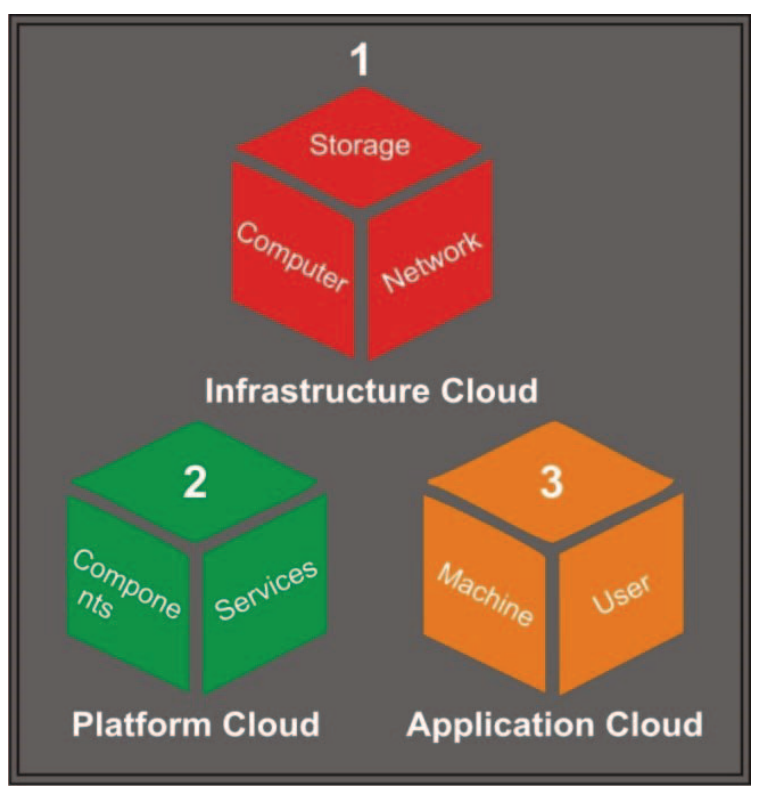

Fig. 2: Models of cloud.

\subsection{Problem Area in the Cloud Data Centre Network (DCN)}

Cloud computing has been well received and generally utilized everywhere. To keep pace with its rapid adoption, service providers must build an ever increasing number of data centres, placing them all around to diminish dormancy to the most extreme conceivable degree for worldwide customers [35]. In cloud situations, flexibility and versatility can be accomplished by expanding or diminishing virtualized framework assets such as virtual machines, yet there are a few issues in overseeing cloud framework on the IaaS level while considering both systems administration asset provisioning and configuring. A large number of networks are making use of a cloud foundation for themselves for dealing with these offices and associating them together. However, the present networking approach utilized in cloud data centre systems is becoming a hurdle to scaling up data centres. In straightforward words, it can neither be effectively organized nor adaptable [36]. With a specific end goal to give cloud benefits, the supplier should construct and keep up at least one vast scale cloud data centre where countless physical hosts are associated through a huge number of system switches [37]. With the high complexity of network connections on a huge scale, the provider needs to think about the DCN with an alternate point of view from the traditional system. Subsequently, it puts an expanding request on the networks and the systems as well [36-37].

\subsection{Software Defined Networking}

SDN is a novel approach in the area of networking [38]. The basic norm behind SDN is the segregation of the Data Plane and the Control Plane. In traditional networking both the intelligence and the forwarding plane are coupled inside proprietary hardware. This increases the complexity and decreases the expandability of the network [39]. With the introduction of SDN in networking, the whole concept of managing the networks has been changed, thereby making them programmable networks that allow the network 
administrator to change the traffic flow from one switch to another with few lines of code. Figure 3 shows the layered architecture of SDN:

a) Physical Layer: It is the layer that includes the infrastructure being used in the network like switches, routers, etc.

b) Control Layer: It is the main layer where the SDN controller resides and provides various network services and provisioning [40].

c) Application Layer: SDN architecture's topmost layer is the application layer. It includes all applications like firewall, load balancer, etc. [38, 39].

d) API's (Application Programming Interface): To provide the communication between various layers there are some well-defined API's such as Southbound API (e.g. OpenFlow protocol) and Northbound API (e.g. REST). [40].

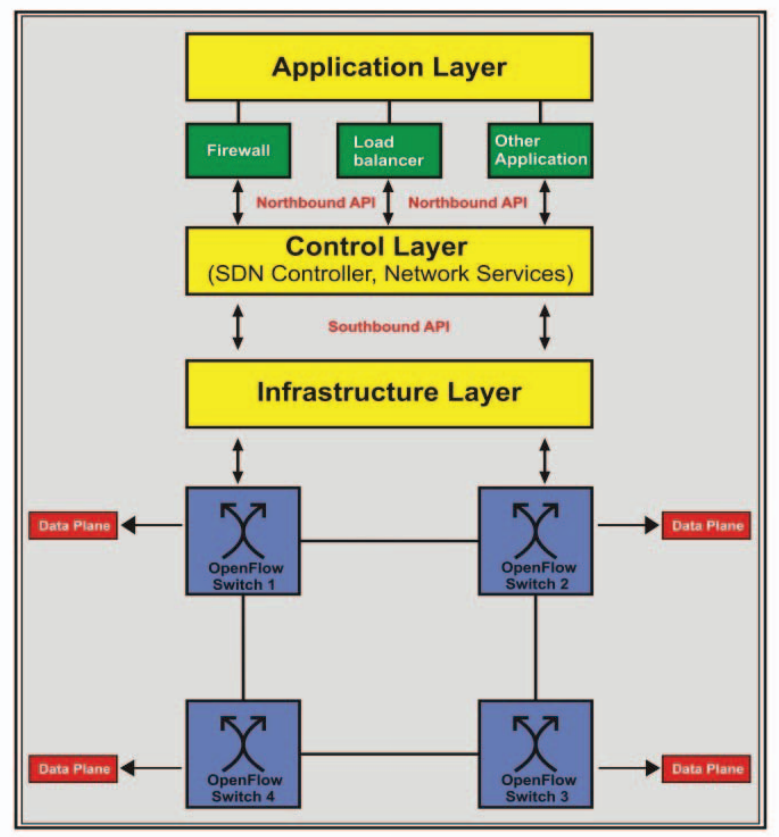

Fig. 3: Architecture of SDN.

Since the bond between sending equipment (or forwarding plane) and control logic has been separated in the case of SDN, so it provides more options to institutions and researchers for establishing new system administration conventions, traffic administration, virtualization, and programming advancements [41]. It prompted the presentation of OpenFlow in which aggregate consequences of various associations are and turn into an accepted standard convention for SDN controllers. Numerous controllers have been presented and effectively created in light of OpenFlow such as RYU, Floodlight, RYU, POX, Open Daylight etc. SDN has likewise opened up inventive open doors in transit of building up the controlling rationale of systems [41, 42]. In traditional systems, the control plane is exclusively created by substantial switch merchants, for example vendors such as Juniper or Cisco, that are combined to equip network hardware and hence make the network devices vendor-specific [41-43]. As the sending equipment is isolated and completely maintained by the SDN controller, programming with respect to SDN based network, various control logic can be combined and executed since it takes after SDN standard, for e.g., OpenFlow. Figure 4 demonstrates the correlation design of traditional network administration and SDN. In this way, SDN has encouraged advancements in the 
improvement of different type of system intelligence or the control logic that might have been abundantly restricted in the approach used by conventional systems [43, 44].

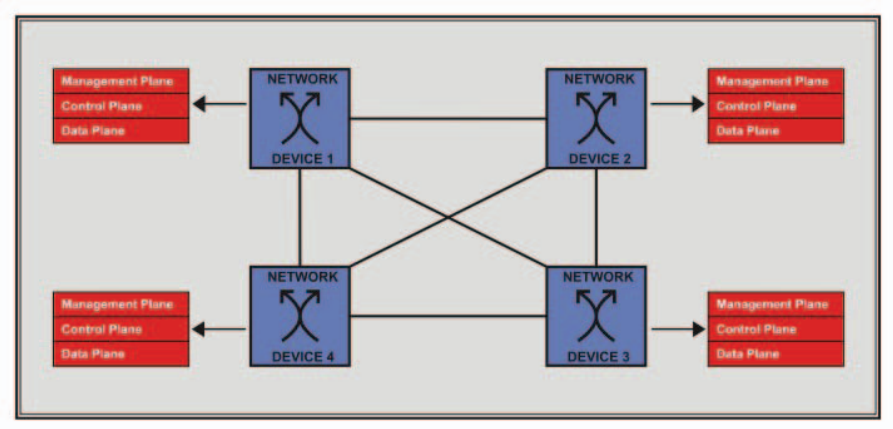

Fig. 4: Network architecture of traditional networks.

\section{SDN ENABLED CLOUD COMPUTING}

Combining SDN and cloud gives birth to new methods and possibilities through which new interfaces automatically become programmable [45]. Although there has been a tremendous rise in the field of cloud computing, those that are playing the vital role of managing cloud networks are facing a significant challenges on which the overall performance is dependent [46-47]. The issues in cloud networks include inflexibility, vendor-specific firewalls, scalability, manageability, etc. Consequently, cloud networks need a cloud infrastructure in which the aforementioned disadvantages are absent. In the future of networking SDN is an emerging model; with its basic principle of separation of the intelligence of the networks with the network, hardware with improved flexibility and scalability hence makes cloud networks programmable which increases the manageability and agility [48]. Out of all the issues in cloud networks, scalability is one of the main issues that need to be considered. SDN is the solution that can be used to upgrade the scalability of the cloud and fulfil the need of the hour. SDN can furnish a new architecture which supports the dynamism in network architecture and then further transforms the usual cloud networks into prosperous provider delivery platforms [49-50]. This is the reason for introducing SDN into the cloud. Making use of SDN in cloud computing can be referred to as SDN- Enabled cloud computing. The SDN based cloud is a new type of cloud in which SDN is introduced and network control is at one single place [51]. From centralized SDN controller, instructions to move the traffic from one place to another is provided to other networking devices [52-53]. In the cloud based on SDN, cloud computing extends from server virtualization and centralization as nicely as storage virtualization and centralization to community virtualization and centralization. Recently, clouds based on SDN have attracted first-rate attention [54].

When the SDN based cloud is compared with the traditional network used in the cloud, it has many advantages in terms of Quality of service (QoS), VM orchestration, etc. For the purpose of allocation, a required bandwidth is needed. This requirement of QoS for all the priority cloud users can be met by the SDN based cloud that uses an Open Vswitch [53]. SDN based networks are not only limited to provide the QoS but also live VM management in which the server can interrupt or exploit the information from one end to another. It is also believed that if SDN is implemented in the cloud it can offer new opportunities for network security to be enhanced since cloud-based SDN provides faster reaction and greater flexibility when the condition is getting revised [55]. 


\subsection{Need for Software Defined Cloud Data Centres (SDN-DC)}

To conquer the deficiencies of traditional networks, cloud data centres began embracing the SDN idea in DCN [51]. SDN offers a centralized control plane with a perspective of the whole system. With the help of the controller, it can make use of progressive change in the network. The need for dynamic flow of data from sender to receiver in the cloud environment and its data centres is well suited to SDN because of its centralized controller that can easily dynamically alter the flow of data in the network. On the basis of traditional networking used in DCN architecture, SDN-DC takes over from conventional systems administration hardware with SDN-empowered gadgets [52]. When $\mathrm{SDN}$ is implemented in DC, each system's administration that is a part of that data centre is fitted for implementing the features of SDN and then can convey all the aforementioned advantages to the cloud data centre [53]. SDN-empowered Cloud Computing (SDN-cloud or SDN-empowered clouds) specified to SDN-DC, as well as inter-cloud organizing that consumes the SDN utilization over various data centres and WAN. In this way, SDN benefits can be connected to internetworking domains [54, 55].

A more extensive term SDN-DC has been proposed by Jararweh et al. [8] and Buyya et al. [7] in which the network infrastructure is also software defined rather than only defining the networking. The approach was to construct a completely mechanized cloud server farm enhancing configurations, that was powerful and self-governing. Buyya et al. [7] expanded the idea of virtualization from a virtualized server to every other component in cloud data centres. The centre innovations to empower SDN-DC to incorporate server virtualization, SDN, arrange virtualization, and virtual middle boxes. With advances, the reconfiguration and adjustment of physical assets in SDN-DC has turned out to be more achievable and easier to be executed. The suggested architecture was executed and assessed in the simulation environment. Jararweh et al. [8] likewise considered a framework concentrating on different parts of SDC including capacity, organizing, data centres, virtualization, and security. It assembled an exploratory setup for SDN-DC with the examined components in the study to explain the viability of the proposed programming defined cloud architecture.

SDN-DC is more realistic as it is suggested for research purposes and has not yet been investigated broadly.

\subsection{SDN-enabled Cloud Computing Architecture}

SDN empowered architecture is separated into three layers. Figure 5 explains the abstract architecture of cloud computing empowered by SDN, based on the literature [46, 53-55]. The SDN controller controls the system related capacities, which are associated with the director of the cloud through APIs that are north-bound. SDN highlights such as arranging topology disclosure, virtual system administration; organizing checks and dynamic system designs are empowered through the controller of SDN. Different types of SDN controller can be practical to expand its adaptability through intercommunicating, with the help of east-west-bound APIs. Cloud resources consist of systems and process administration assets. The cloud administrator convinces hosts to run VMs on a hypervisor, though organizing assets like switches are overseen by the SDN controller by refreshing switches of sending tables through south-bound APIs (e.g. OpenFlow). Note that the SDN controller also manages functions of networking in hosts for examples, virtual switches for VM traffic management and network virtualization. 


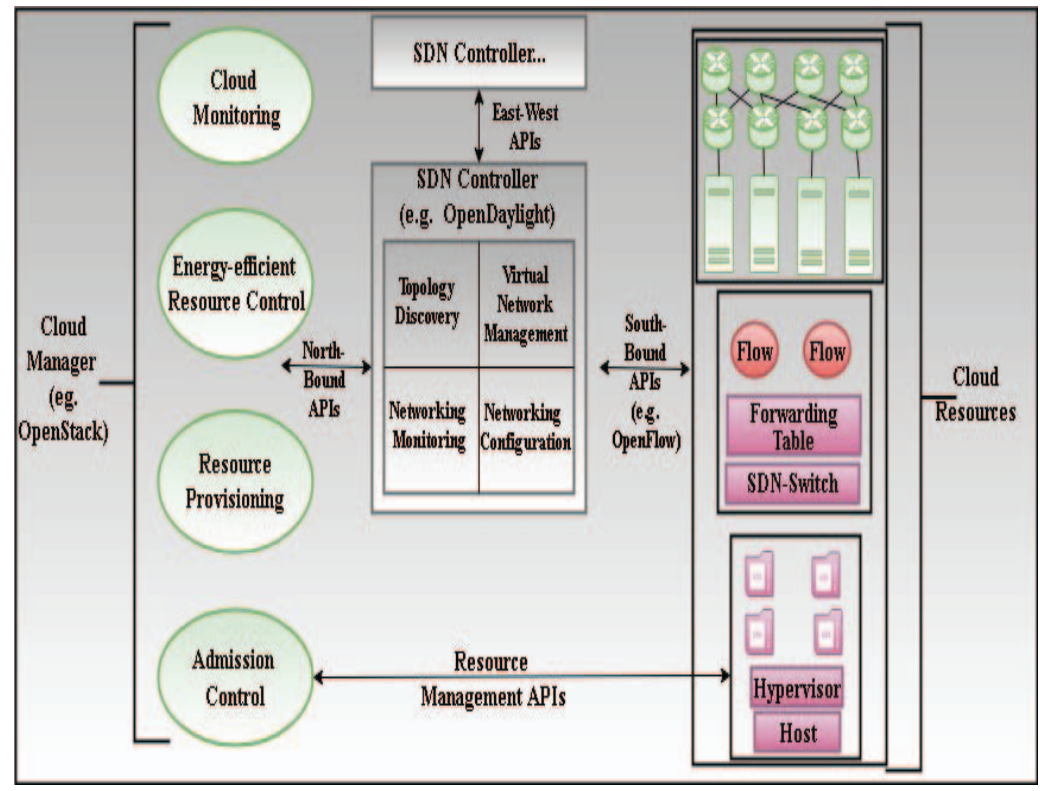

Fig. 5: SDN-enabled cloud architecture.

Recently, Mayoral et al. [56] provided the structure of the cloud with a single SDN controller as well as numerous controllers. The framework arranged the administration of a data centre with the SDN capacity. Keeping in mind the end result to discover the differences between one or more controllers in data centres, the author had assessed the OpenStack [57] architecture and OpenDayLight with respect to SDN. Similarly, the author had also proposed a conclusion to end arrangement of cloud architecture and system assets that oversee the two assets in distributed cloud data centres [58]. Virtual foundations in clouds are powerfully assigned and overseen through the chief. The VM distribution issues were displayed as a mapping figure with switch parameters and arranged joins. Additionally, a set of rules for the calculation of locating the base number of hosts with enough limits was incorporated and chose the shortest way between the hosts. The design of the organization was approved on an exact testbed with OpenVSwitch and OpenStack [57], while the calculation was done in simulation. Fichera et al. [59] exhibited in a detailed testbed setup for the organization of SDN crosswise over the edge, IoT spaces, and cloud in $5 \mathrm{G}$ benefits.

The foundation was comprised of isolated orchestrator(s) for the SDN, cloud, and IoT [60]. The SDN orchestrator oversees the cloud and IoT arrangements as well as the transport organized between them. Over individual orchestrators, the administration orchestrator gets direct benefits provisioning for applications with respect to the client's prerequisites. The proposed framework was examined in a testbed which comprised of ONOS (Open Networking Operating System) controller, OpenStack Cloud and Mininet for the edge arrangement. The Control Orchestration Protocol (COP) was suggested by specialists with respect to different organizations to allow overseeing heterogeneous control planes of SDN and Cloud [60]. While OpenFlow means controlling of messages between switches and the SDN controller as the controller southbound interfaces, COP is accountable for organizing among SDN controllers in various system and in addition controllers of cloud working north of controllers. COP brought together transport API for arranging diverse transport in the inter-cloud condition. This convention gives a deliberation of asset topology disclosure, provisioning and way calculation. It was approved through 2 proof-of-idea tests for organizing asset recovery and provisioning [60]. 


\section{SDN BASED IOT CLOUD}

The boom of IoT and the quick enhancement of related applied sciences create an extensive connection of "things." Cloud computing is a field for creating big storage statistics and analysis. IoT is attractive on its own, but the enormous amount of data coming from IoT devices, its storage, big data statistics, and analysis must be performed by cloud computing. Real innovation will only come if IoT and cloud computing combine. The aggregation of both cloud computing and IoT will enable new services for monitoring and processing data. For example, sensory information from IoT devices can be uploaded and stored with cloud computing. This data can later be used for statistical analysis and decision making.

In truth, cloud computing and IoT are tightly coupled and are closely related to each other in a similar way that an automobile and gasoline are related. The strength produced with the aid of gas (the IoT) runs the vehicle (Cloud Computing). IoT is no longer solely about connecting random devices nearby and making robots. IoT is an imaginative and prescient tool whereby we are able to talk to gadgets near us in such a way that we can make informed decisions based totally on the statistics accrued by means of these devices.

One of the vital desires of cloud providers is to provide availability to their customers. To supply versatile guide of their clients, cloud vendors work with more than a few fact facilities over distinct geolocations with virtualized asset provisioning. Substantial massive records centres are comprised of heaps of switches interfacing countless servers. Every server can serve a number of utility needs from more than a few consumers by making use of virtualization advances, which have been increased inconceivably in preparation and capacity belongings for the most recent few many years yet not in network resources. As of now, cloud clients can lease virtualized processing assets, i.e., virtualized storage, and virtual machine from various cloud providers that are fixed surely for the client. Be that as it may, the machine asset virtualization innovation is nevertheless a lengthy way from being used in industrial public clouds.

Therefore, it can be concluded that as the data from IoT devices is coming in a huge manner, we need a cloud infrastructure in such a way that it has the capability to handle the rate of growth of the network. SDN has the capability to achieve this. Therefore, if SDN is implemented in the cloud it can increase the capability, efficiency of cloud storage and hence this cloud is called an SDN based IoT cloud.

\subsection{Issues in SDN-Based IoT Cloud}

A wide variety of gadgets enabled with IoT which are used to supply these applications, consisting of actuators, sensors and cellular devices. Communication among devices with one another is done through an integrated community that may additionally be defining the media type i.e. wireless or wired. It constructs the IoT in more necessary theme in its existence in daily practices which offers with the circumstances and the surrounding occasions such as fitness care, commercial agency administration, factories, automation, climate forecasting and many greater areas. Imagine the amount of records generated by means of 10 such government places of work and the quantity of computing power wanted to manage this information. Here, Cloud Computing comes into play. Hence the records gathered via IoT units is stored and processed on the Cloud and primarily based on our learning and processing of that information choices like building renovation, electrical faults, building lifespan is detected. The IoT is generating an extraordinary quantity of data, which in turn places a notable pressure on the Internet 
infrastructure. As a result, businesses are working to locate methods to alleviate that stress and resolve the facts problem.

Another problem is Heterogeneity- meaning that IoT objects are changing in their properties and characteristics. As the numbers of devices are increasing day by day different vendors are coming into play to provide the services to various users. Devices that are communicating and getting the services are from different vendors is very hard to manage.

The need to combine SDN and IoT is to compile and resolve many types of issues that will be propagated as the IoT network grows. By making use of SDN, in an IoT network, the IoT controller, which is a high-level module, will interact with the centralized SDN controller for planning and organizing the network and performing the functions related to the IoT.

\subsection{SDN-Based IoT Cloud Architecture}

SDN-empowered architecture is separated into 3 layers. Figure 6 demonstrates the summary shapes of simple SDN-empowered cloud computing structure obtained from the literature. System-related capacities are managed by the SDN controller, which is related to the director of the cloud via northbound APIs. SDN highlights, for example, organize topology disclosure, prepare checking, virtual machine administration and dynamic system designs, are empowered via the SDN Controller. Various SDN Controllers can be sensible to lengthen adaptability through the ability to intercommunicate through the potential of east-west-bound APIs. The cloud property consists of buildings and manner administration assets. Hosts are managed by the network administrator of the cloud for running VMs on a hypervisor, although organizing property like switches is overseen using the SDN controller through clean sending of tables in switches with the resource of southbound APIs. It is very important to understand the fact that the SDN controller manages features of networking in hosts, for example, for community virtualization, VM visitor's administration, and digital switches.

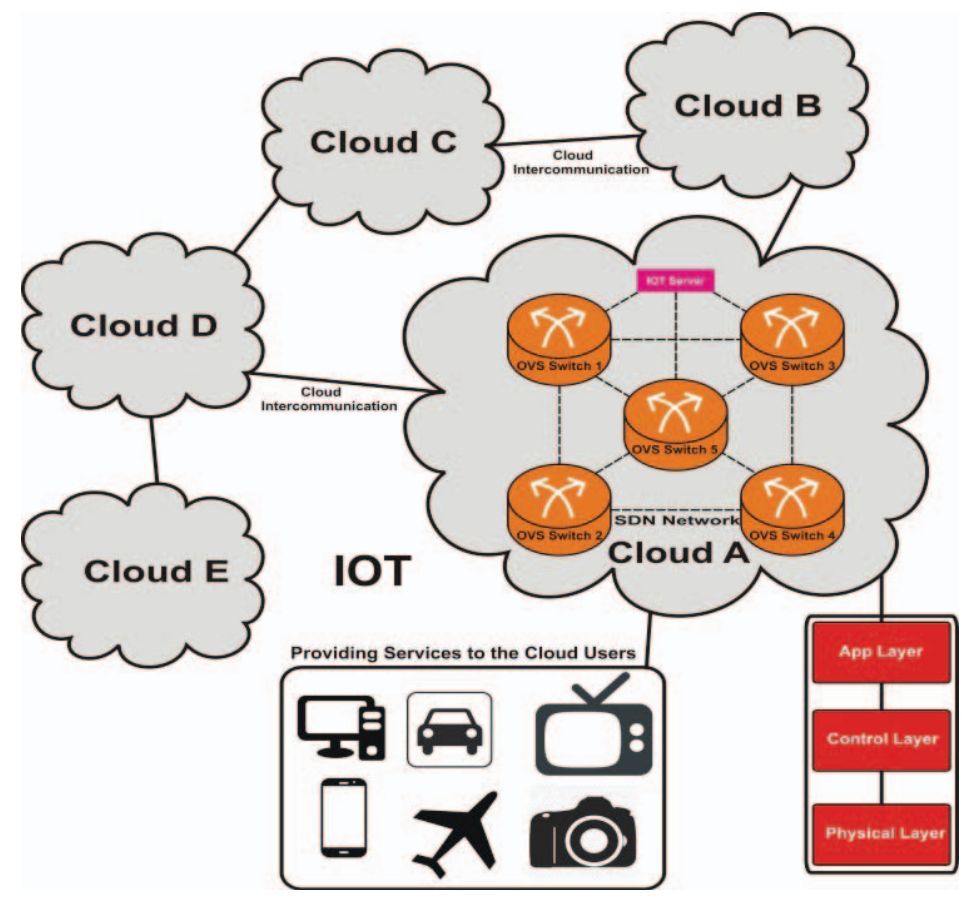

Fig. 6: SDN-based IoT cloud. 


\subsection{Good Features of SDN for Offering Protection in SDN-Enabled IoT and Cloud Computing}

- Separation of the control plane from the data plane: SDN decouples the intelligence of the network and management plane which constitutes the networking devices. Hence it permits setting up, besides troubles of large-scale attack and safety experiments. The high configurability of SDN not only allows the network administrator to have clarity among the digital networks but also how to enable experiments on a true environment.

- Centralized Controller and its vision: The SDN controller has a full vision and control over the network including traffic monitoring, shaping, switches flow table updating etc. Centralized manipulation of SDN controller allows dynamically resisting threats and attacks as well.

- Analysis of traffic: Network traffic can be examined on the basis of evaluation which is a software-based and which is ultimately enables the innovation, as it is possible to enhance the capabilities to change the usage of any technique which is a software-based. Analysis of the network traffic can be carried out in a real-time environment using desktop and getting to know algorithms used, backup databases and any other specific software program tool.

- Dynamic updating the flow tables: Flow tables of switches can be dynamically updated through a centralized SDN controller which further helps to prevent much security threats in the network.

\section{EVALUATION METHOD AND TECHNOLOGY}

For quickening improvement and advancement of SDN-empowered cloud computing, toolboxes and devices are required to manufacture a testbed for testing SDN and OpenFlow frameworks in a cloud data centre. The testbed also has the ability to quantify the vitality utilization to assess proposed algorithms. In this section, observational and simulation techniques are clarified as shown in Fig. 7.

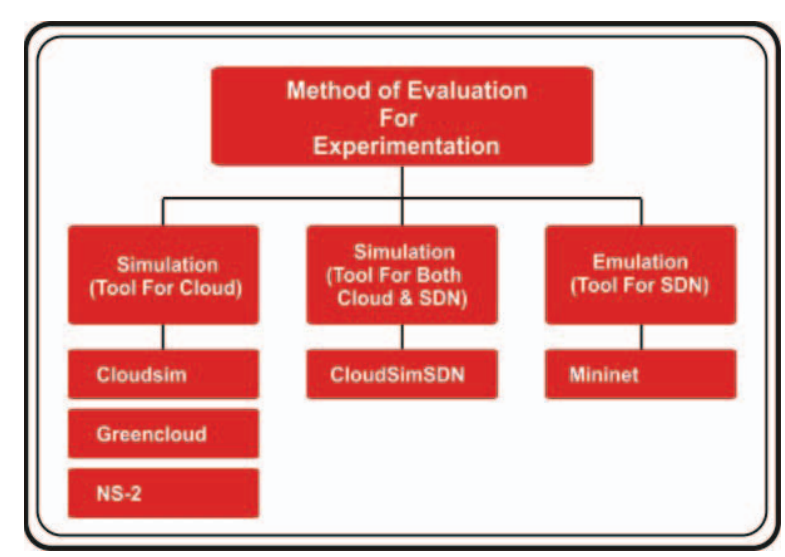

Fig. 7: Evaluation method.

\subsection{Simulation Platforms for Cloud}

Simulation is the first and initial tool for new research and experimental setups. Real Infrastructures are utilized to archetype the performance of the application under certain conditions like patterns of workload, reliability, etc. One of the major examples of 
invariable frameworks is Microsoft Azure, Amazon EC2, etc. Therefore, this makes the transcription of results authentic and extremely considerable. On the other hand, it is timeconsuming and unvaried to re-configure the parameters across a large-scale. There are some restrictions for the developers as the environment of the cloud is not in the control of them under certain circumstances. Thus, archetype practices in scaling, depending as well as repeating is impossible to execute in the real-world surroundings. An alternative tool that can open up the probability to examine the hypothesis in a manageable environment is a simulation tool. It can also easily recreate the outputs. IT Organizations get remarkable benefits from these kinds of tools.

The simulation platform gives a controlled and reproducible condition for assessment effortlessly of change and setup. For cloud computing, a number of simulation tools have been introduced to evaluate new ways to deal with controlling and overseeing the cloud server farm and different type of situations. CloudSim [61] is a prominent cloud test system executed in Java, giving a discrete occasion-based simulation equipped for mimicking cloud server, VMs, intermediaries, and hosts. Different scenarios can be executed in CloudSim, including the VM position approach, VM relocation arrangements, facilitating strategy and other server farm administration strategy [61]. It likewise bolsters workload reproduction executing in the VMs. With its simple to-utilize discrete occasionbased design, extra components can be added to send and get re-enactment occasions and in addition, stretching out the recent elements to give additional usefulness. As far as there is a concern of network events there is no support available by CloudSim in details [61].

To satisfy the lack or unavailability of system reproduction capacity of CloudSim, NetworkCloudSim [62] is acquainted with re-enacting applications with organizing correspondence assignments. Extra system components are included NetworkCloudSim, including system switches and connections that get arrange occasions and ascertain evaluated organize transmission time. In spite of the fact that NetworkCloudSim [62] incorporates broad system usefulness to mimic server farm system and various applications for message transferring within a data centre, the use of SDN in the experiment execution of CloudSim is clearly not supported [62].

GreenCloud [63] is another NS-2 [64] a based system which is based on a simulation that catches the vitality part of various cloud data centres comprising registration and correspondence of components. With the joining of NS-2 [64], which can catch the system design precisely on the bundle level, GreenCloud [63] can likewise give exact system comes about. The recreation substances incorporate has and switches with control utilization models, for example, DVFS. Workload models are likewise predefined and given in the system to three sorts of occupations, e.g., figure concentrated, information escalated, and adjusted. In NS-2 there is an availability of simulated environment which helps to provide a comprehensive framework with respect to clouds but there is no support for evaluation of SDN based applications.

\subsection{Emulation Platform for SDN Networks}

In order to create the network virtual host, switches and controller links between them to create a network emulated is used called as Mininet [65] emulator. Standard Linux network software is run by Mininet hosts, and Mininet switches support OpenFlow protocol for the purpose of communication and highly flexible custom routing and ultimately creating the networks which are software defined. Mininet not only is a good platform which is useful in providing support to research and developing applications but it is also helpful in making prototypes of networks, debug the networks and then perform testing on them. With the help of Mininet, a complete network including topologies, 
server, and everything can be emulated and created in a single laptop. Mininet is the best emulation platform to emulate SDN networks in the absence of real hardware [66].

For SDN support in CloudSim, CloudSimSDN [67] was as of late acquainted with empower mimicking SDN highlights, for example, flexible transfer speed distribution or dynamic system setup. CloudSimSDN [67] is aimed to provide and simulate the highlighted features of SDN that further can be transferred in cloud data centres. Utilizing CloudSimSDN centralized SDN controller can be actualized inside the test system to imitate the conduct of the controller to reduce the unpredictability of copying the OpenFlow controller in the recreation [67]. Despite the fact that it gives just basic outcomes in systems administration reproduction, the disentangled engineering furnishes basic outcomes etc. with the help of SDN features in a very small period of time [67].

Teixeira et al. [68] proposed collaboration of Python-based SDN OpenFlow controller POX with Mininet to support simulation and making use of SDN features in cloud computing. To organize the network topologies Mininet is used to imitate them information activity and then organizing topologies within a data centre in which there is already a presence of OpenFlow SDN controller. By collaborating POX and Mininet, it helps to give handy outcomes and then preparing to-utilize programming. But still, this simulation tool suffers from many cons with respect to help or need in cloud-highlights, for example, characterizing different VM writes or execution of heterogeneous application workloads at the host through simulation.

\subsection{Evaluation Method for Collaborating Both SDN and Cloud}

To overcome the disadvantages occurred in various simulations and emulation tools discussed above. CloudSimSDN [67] has accomplished the task of combining SDN and Cloud together. It is a new simulation tool that provides the framework for SDN networks and Cloud. On top of CloudSim simulator, this new simulation tool is built. CloudSimSDN [67] includes the configuration and dynamic management of the resources which are managed and configure in a cloud data centre through a single point of control that is the SDN controller. The designing and formulation of this framework is done in such a way that it has the ability to perform the evaluation of all the resource management policies and strategies and ultimately which are to be used and appropriate for various SDN-ready cloud data centres [67].

With the help of CloudSimSDN simulation is performed of various cloud data centres, machines, switches in the network, links in between the network, and topologies (virtual) in network. This simulation is performed in order to calculate the approximated values of performance metrics which ultimately guarantees the Quality of service and less energy consumption to satisfy the needs of the environment conservation [67].

\subsection{Real Platform}

OpenStackEmu [57] is providing a platform for the consolidation of a network using emulation with SDN and OpenStack. ONO and ODL (OpenDayLight) [69] are the largest open-source SDN controllers that are making it possible for the SDN to join with OpenStack by means of modules. Modules in the OpenStack suite such as neutron can be designed to utilize as an alternate to the SDN controller rather than utilizing Neutron's own particular capacities. 


\section{CHALLENGES TO SDN BASED CLOUD}

Despite the fact that SDN-based cloud demonstrates numerous great highlights, it faces a few difficulties that must be considered, including execution, accessibility, and versatility security. Although numerous examinations have explored the utilization of SDN innovation in cloud computing, there are as yet a few perspectives that have not been investigated exhaustively [70-71].

\subsection{Execution}

Execution refers to the system hub for the preparing pace considering both latency and throughput [72]. The strategy for SDN was to deal with new packets which bring the network programmability. But, at the same time, it produces execution issues. The authors [73] had explained that nowadays controllers cannot deal with a huge number of flows in connections of $10 \mathrm{Gbps}$. So the question is how to keep programmability which is requiring for additional examination and to enhance execution.

\subsection{Accessibility}

The duration or the time in which the framework of SDN is in running condition is called accessibility. In the SDN network as there is a dependency on the single centralized controller. Though it brings the programmability, on the other hand, it also brings a challenge with respect to accessibility. One of the advantages that the traditional distributed network architecture is comprised of is that if a switch fails, the accessibility of the system does not affect and still can be looked for [74]. But on the other hand in the SDN network if a single point of control i.e. SDN controller fails the whole network collapses and then the accessibility of the system might be lost completely.

\subsection{Scalability}

It is the ability to increase the network infrastructure so that it can easily incorporate the demand or need for network growth. Then centralized single SDN controller can be converted into a bottleneck of versatility [75]. By introducing peer-with-peer or distributed controller foundation it may share the communication weight to the controller. It may be, a general system view is required to coordinate the correspondences between the controllers utilizing the westward and eastward APIs. Behind controller adaptability, there are some other versatility concerns including the overhead of flow setup and flexibility to failures.

One of the basic issues that need to be addressed is the scalability of the SDN controller [77]. SDN controller accumulates data from the whole system and then handles each and every individual network switch individually; this process makes the controller adaptable and keeps the single point of failure at the controller. In the cloud, this entanglement can become a critical issue because of the size multiple-sided quality of DCN and the normal SLA for the supplier [77]. The SDN controller for the cloud DCN can without much of a stretch turn into a solitary purpose of disappointment as controllers in the DCN can be over-burden because of the gigantic number of network switches. The aforementioned issue can be handled by disseminating controllers or by implementing a proactive approach while communicating between the SDN controller and switch [77].

\subsection{Virtualization}

Previously, NFV is provided by middle boxes, which are embedded with dedicated hardware, such as load balancer, firewall and intrusion detectors. These dedicated and vendor specific hardware devices are meant to perform the single task only and they don't 
allow the network administrator to reconfigure their codes and hence hardware inflexibility is there which ultimately reduces the cost-effectiveness. Many researchers have already attempted to alter the hardware of middle boxes with a series of SDN switches which are embedded with specific controller programs [5].

\subsection{Security}

As compared to traditional networking SDN brings separation of intelligence of the SDN network constitutes in the control plane and network devices from the data plane. Due to this, there is an increase in the rise of security attacks [78]. Security investigation has demonstrated that the SDN system endures numerous security dangers, including:

1) unapproved get to, e.g., the unapproved controller gets to or unauthenticated application get to.

2) information spillage, e.g., flow control disclosure (side station assault on input cushion) sending strategy revelation (parcel handling timing examination),

3) Alteration in the information, e.g., modification in flow run to alter bundles [78-79].

4) noxious applications, e.g., false run addition controller commandeering.

5) Issues in configuration e.g., absence of TLS (or other verification strategies) reception strategy requirement.

6) Denial of service, e.g., while providing communication between switch-controller there may occur a switch or controller table flooding [80].

For various available open cloud providers, the most important aspect that needs to be addressed is security. While accessing the cloud services user's information is an important factor. Although security in cloud data centres has been explored broadly with multiple methodologies, collaborating SDN into it can make it vulnerable [81]. So, research can be directed towards providing security to the SDN enabled cloud data centres [82-83].

\subsection{Energy Efficiency}

Cloud data centres are consuming a huge amount of electricity which is increasing very rapidly. In 2013, 91 billion kilowatt-hours energy was consumed by US data centres, which is more than enough to power all households in NYC for 2 years. It is even expected that by 2020 it will be increased to approximately 140 billion kilowatt-hours which will cost the US \$13 [7] billions annually. Therefore to improve energy efficiency while computing the cloud is becoming a most important research problem in both academics and in industries. There are already many researchers who are working in this area to optimize energy efficiency [7]. With the recent introduction of SDN, the technology of joint optimization is feasible and it can be explored in order to save maximum energy and therefore providing best QoS [7, 84].

\subsection{Network Function Virtualization}

DCN is comprised of many numbers of devices, these devices communicate with each other through multiple switches and devices and virtualization of the network in it is quite difficult because of the complexity of the network. There are gaps which are found while realizing virtualization of the network in clouds, which can be diminished by making of SDN. Although traditional networking technologies as VPN and VLAN not only accepted by industry is making use of them. But by combining SDN with the traditional methods can take even more flexibility, programmability, and security to 
clouds. Thus for further research, virtualization of the network can be explored in a cloud data center.

\subsection{System Function Virtualization}

There are gaps in acknowledging virtualization of the system in the cloud, which can be feasible with the coordination of SDN [7]. Though the customary systems administration advancements, like VPN and VLAN has been broadly embraced in industry, co-ordination of SDN with the conventional technologies can bring much better execution and more adaptability to the cloud. Along with SDN, streams among VMs can be controlled more finely all the powerfulness and adaptability by adjusting the evolving activity. Progressively, switches can be continuously arranged in the supervision of the controller, which can direct the whole network. Therefore, virtualization of the network for SLA network guarantee is possible can be investigated in cloud data centres and introducing research in $[7,84]$.

\section{FINAL REMARKS AND CONCLUSION}

Use of IoT devices is increasing day by day. The foundation behind cloud networks, cloud computing, is making use of large networks to fulfil user demands. The cloud network is growing at a very fast pace but by making use of traditional networks, cloud networking is suffering from inflexibility, less manageability, and vendor specificity. To overcome the situation, SDN can be used in cloud data centre networks. SDN not only achieves programmability, agility, manageability but removes the barrier of vendorspecific by using the principle of separating the control plane and data plane. The job of the network administrator to overlook the network and managing the network can be easily achieved.

In this paper, an overview of traditional networking used in cloud computing with its disadvantages and how SDN can improve its functionality is described. This paper discussed the related work in this collaboration various limitations and advantages of their work is also surveyed. In order to implement cloud and SDN, this paper would be contributing to researchers. Various simulation and emulation platforms for performing the experiments are also discussed. At last research directions towards SDN based cloud are also provided.

\section{REFERENCES}

[1] Senyo, P. K., Effah, J., \& Addae, E. (2016). Preliminary insight into cloud computing adoption in a developing country. Journal of Enterprise Information Management, 29(4), 505-524.

[2] Buyya, R., Yeo, C. S., Venugopal, S., Broberg, J., \& Brandic, I. (2009). Cloud computing and emerging IT platforms: Vision, hype, and reality for delivering computing as the 5 th utility. Future Generation computer systems, 25(6), 599-616.

[3] Senyo, P. K., Addae, E., \& Boateng, R. (2018). Cloud computing research: A review of research themes, frameworks, methods and future research directions. International Journal of Information Management, 38(1), 128-139.

[4] Bayramusta, M., \& Nasir, V. A. (2016). A fad or future of IT? : A comprehensive literature review on the cloud computing research. International Journal of Information Management, 36(4), 635-644.

[5] Son, J., \& Buyya, R. (2018). A Taxonomy of Software-Defined Networking (SDN)-Enabled Cloud Computing. ACM Computing Surveys (CSUR), 51(3), 59. 
[6] Al-Fares, M., Loukissas, A. and Vahdat, A., (2008), August. A scalable, commodity data center network architecture. In ACM SIGCOMM Computer Communication Review, Vol. 38, No. 4, pp. 63-74.

[7] Buyya, R., Calheiros, R.N., Son, J., Dastjerdi, A.V. and Yoon, Y., (2014), September. Software-defined cloud computing: Architectural elements and open challenges. In Advances in Computing, Communications and Informatics (ICACCI, 2014 International Conference on (pp. 1-12). IEEE.

[8] Jararweh, Y., Al-Ayyoub, M., Benkhelifa, E., Vouk, M. and Rindos, A.,( 2016). Software defined cloud: Survey, system and evaluation. Future Generation Computer Systems, 58, pp.56-74.

[9] Kreutz, D., Ramos, F.M., Verissimo, P.E., Rothenberg, C.E., Azodolmolky, S. and Uhlig, S., (2015). Software-defined networking: A comprehensive survey. Proceedings of the IEEE, 103(1), pp.14-76.

[10] Badotra, S. and Singh, J., (2017). A Review Paper on Software Defined Networking. International Journal of Advanced Research in Computer Science, 8(3).

[11] McKeown, N., Anderson, T., Balakrishnan, H., Parulkar, G., Peterson, L., Rexford, J., Shenker, S. and Turner, J., (2008). OpenFlow: enabling innovation in campus networks. ACM SIGCOMM Computer Communication Review, 38(2), pp.69-74.

[12] Lantz, B., Heller, B. and McKeown, N., (2010), October. A network in a laptop: rapid prototyping for software-defined networks. In Proceedings of the 9th ACM SIGCOMM Workshop on Hot Topics in Networks (p. 19). ACM.

[13] Vahdat, A., Clark, D. and Rexford, J., (2015). A purpose-built global network: Google's move to SDN. Queue, 13(8), p.100.

[14] Toosi, A.N., Calheiros, R.N. and Buyya, R., (2014). Interconnected cloud computing environments: Challenges, taxonomy, and survey. ACM Computing Surveys (CSUR), 47(1), p.7.

[15] Mastelic, T., Oleksiak, A., Claussen, H., Brandic, I., Pierson, J.M. and Vasilakos, A.V., (2015). Cloud computing: Survey on energy efficiency. Acm computing surveys (csur), 47(2), p.33.

[16] Jararweh, Y., Al-Ayyoub, M., Benkhelifa, E., Vouk, M. and Rindos, A., (2016). Software defined cloud: Survey, system and evaluation. Future Generation Computer Systems, 58, pp.56-74.

[17] Azodolmolky, S., Wieder, P. and Yahyapour, R., (2013), June. SDN-based cloud computing networking. In Transparent Optical Networks (ICTON), 2013 15th International Conference on (pp. 1-4). IEEE.

[18] Yen, T.C. and Su, C.S., (2014), April. An SDN-based cloud computing architecture and its mathematical model. In Information Science, Electronics and Electrical Engineering (ISEEE), 2014 International Conference on (Vol. 3, pp. 1728-1731). IEEE.

[19] Buyya, R., Broberg, J. and Goscinski, A.M. eds., (2010). Cloud computing: Principles and paradigms (Vol. 87). John Wiley \& Sons.

[20] Grover, J. and Sharma, M., (2014), July. Cloud computing and its security issues-A review. In Computing, Communication and Networking Technologies (ICCCNT), 2014 International Conference on (pp. 1-5). IEEE.

[21] Yang, H., \& Tate, M. (2012). A descriptive literature review and classification of cloud computing research. Communications of the Association for Information Systems, 31(1), 2.

[22] Kaur, S. and Singh, A., (2012). The concept of cloud computing and issues regarding its privacy and security. International Journal of Engineering Research \& Technology (IJERT), 1(3).

[23] Choo, K.K.R., (2010). Cloud computing: challenges and future directions. Trends and Issues in Crime and Criminal justice, (400), p.1.

[24] Zhang, Q., Cheng, L. and Boutaba, R., (2010). Cloud computing: state-of-the-art and research challenges. Journal of internet services and applications, 1(1), pp.7-18.

[25] Kumar, D.K., Rao, D.G.V. and Rao, D.G.S., (2012). Cloud computing: An analysis of its challenges \& security issues. International Journal of Computer Science and Network (IJCSN), 1(5). 
[26] Dogra, N. and Kaur, H., (2013). Cloud computing security: issues and concerns. International Journal of Emerging Technology and Advanced Engineering, 3(3).

[27] Al-Fares, M., Loukissas, A. and Vahdat, A., (2008), August. A scalable, commodity data center network architecture. In ACM SIGCOMM Computer Communication Review (Vol. 38, No. 4, pp. 63-74). ACM

[28] Clos, C., (1953). A study of non-blocking switching networks. Bell System Technical Journal, 32(2), pp.406-424.

[29] Guo, C., Wu, H., Tan, K., Shi, L., Zhang, Y. and Lu, S., (2008), August. Dcell: a scalable and fault-tolerant network structure for data centers. In ACM SIGCOMM Computer Communication Review (Vol. 38, No. 4, pp. 75-86). ACM.

[30] Guo, C., Lu, G., Li, D., Wu, H., Zhang, X., Shi, Y., Tian, C., Zhang, Y. and Lu, S., (2009). BCube: a high performance, server-centric network architecture for modular data centers. ACM SIGCOMM Computer Communication Review, 39(4), pp.63-74.

[31] Zhang, Z., Deng, Y., Min, G., Xie, J. and Huang, S., (2017). ExCCC-DCN: A highly scalable, cost-effective and energy-efficient data center structure. IEEE Transactions on Parallel and Distributed Systems, 28(4), pp.1046-1060.

[32] Bilal, K., Malik, S.U.R., Khalid, O., Hameed, A., Alvarez, E., Wijaysekara, V., Irfan, R., Shrestha, S., Dwivedy, D., Ali, M. and Khan, U.S., (2014). A taxonomy and survey on green data center networks. Future Generation Computer Systems, 36, pp.189-208

[33] Chen, T., Gao, X. and Chen, G.,(2016). The features, hardware, and architectures of data center networks: A survey. Journal of Parallel and Distributed Computing, 96, pp.45-74.

[34] Xia, W., Zhao, P., Wen, Y. and Xie, H., (2017). A survey on data center networking (DCN): Infrastructure and operations. IEEE communications surveys \& tutorials, 19(1), pp.640-656.

[35] Bari, M.F., Boutaba, R., Esteves, R., Granville, L.Z., Podlesny, M., Rabbani, M.G., Zhang, Q. and Zhani, M.F., (2013). Data center network virtualization: A survey. IEEE Communications Surveys \& Tutorials, 15(2), pp.909-928.

[36] He, T., Toosi, A. N., \& Buyya, R. (2019). Performance evaluation of live virtual machine migration in SDN-enabled cloud data centers. Journal of Parallel and Distributed Computing, 131, 55-68.

[37] Abts, D., Marty, M.R., Wells, P.M., Klausler, P. and Liu, H., (2010). Energy proportional datacenter networks. ACM SIGARCH Computer Architecture News, 38(3), pp.338-347.

[38] Amarasinghe, H., Jarray, A. and Karmouch, A., (2017), May. Fault-tolerant IaaS management for networked cloud infrastructure with SDN. In Communications (ICC), 2017 IEEE International Conference on (pp. 1-7). IEEE.

[39] Nunes, B.A.A., Mendonca, M., Nguyen, X.N., Obraczka, K. and Turletti, T., (2014). A survey of software-defined networking: Past, present, and future of programmable networks. IEEE Communications Surveys \& Tutorials, 16(3), pp.1617-1634.

[40] Alsaeedi, M., Mohamad, M. M., \& Al-Roubaiey, A. A. (2019). Toward Adaptive and Scalable OpenFlow-SDN Flow Control: A Survey. IEEE Access, 7, 107346-107379.

[41] Bilal, R., \& Khan, B. M. (2019). Software-Defined Networks (SDN): A Survey. In Handbook of Research on Cloud Computing and Big Data Applications in IoT (pp. 516536). IGI Global.

[42] T Karakus, M., \& Durresi, A. (2017). A survey: Control plane scalability issues and approaches in software-defined networking (SDN). Computer Networks, 112, 279-293.

[43] Kim, H. and Feamster, N.,(2013). Improving network management with software defined networking. IEEE Communications Magazine, 51(2), pp.114-119.

[44] Jarraya, Y., Madi, T. and Debbabi, M., (2014). A survey and a layered taxonomy of software-defined networking. IEEE communications surveys \& tutorials, 16(4), pp.19551980 .

[45] Azodolmolky, S., Wieder, P. and Yahyapour, R., (2013). Cloud computing networking: Challenges and opportunities for innovations. IEEE Communications Magazine, 51(7), pp.54-62.

[46] Banikazemi, M., Olshefski, D., Shaikh, A., Tracey, J. and Wang, G., (2013). Meridian: an SDN platform for cloud network services. IEEE Communications Magazine, 51(2), pp.120127. 
[47] Priya, I. D., \& Silas, S. (2019). A Survey on Research Challenges and Applications in Empowering the SDN-Based Internet of Things. In Advances in Big Data and Cloud Computing (pp. 457-467). Springer, Singapore.

[48] Yan, Q., Yu, F.R., Gong, Q. and Li, J., (2016). Software-defined networking (SDN) and distributed denial of service (DDoS) attacks in cloud computing environments: A survey, some research issues, and challenges. IEEE Communications Surveys \& Tutorials, 18(1), pp.602-622.

[49] Jain, R. and Paul, S.,( 2013). Network virtualization and software defined networking for cloud computing: a survey. IEEE Communications Magazine, 51(11), pp.24-31.

[50] Ma, Y.W., Chen, Y.C. and Chen, J.L., (2017), February. SDN-enabled network virtualization for industry 4.0 based on IoTs and cloud computing. In Advanced Communication Technology (ICACT), 2017 19th International Conference on (pp. 199202). IEEE.

[51] Li, F., Cao, J., Wang, X., Sun, Y. and Sahni, Y., (2017), June. Enabling Software Defined Networking with QoS Guarantee for Cloud Applications. In 2017 IEEE 10th International Conference on Cloud Computing (CLOUD) (pp. 130-137). IEEE.

[52] Bruschi, R., Davoli, F., Lago, P., Lombardo, A., Lombardo, C., Rametta, C. and Schembra, G., (2017). An SDN/NFV Platform for Personal Cloud Services. IEEE Transactions on Network and Service Management, 14(4), pp.1143-1156.

[53] Papagianni, C., Androulidakis, G. and Papavassiliou, S., (2014), February. Virtual topology mapping in SDN-enabled clouds. In Network Cloud Computing and Applications (NCCA), 2014 IEEE 3rd Symposium on (pp. 62-67). IEEE.

[54] Alhazmi, K., Shami, A. and Refaey, A., (2017). Optimized provisioning of SDN-enabled virtual networks in geo-distributed cloud computing datacenters. Journal of Communications and Networks, 19(4), pp.402-415.

[55] Nguyen, T. G., Phan, T. V., Nguyen, B. T., So-In, C., Baig, Z. A., \& Sanguanpong, S. (2019). SeArch: A Collaborative and Intelligent NIDS Architecture for SDN-Based Cloud IoT Networks. IEEE access, 7, 107678-107694.

[56] Buyya, R., Yeo, C.S., Venugopal, S., Broberg, J. and Brandic, I., (2009). Cloud computing and emerging IT platforms: Vision, hype, and reality for delivering computing as the 5th utility. Future Generation computer systems, 25(6), pp.599-616.

[57] Son, J., Dastjerdi, A.V., Calheiros, R.N. and Buyya, R., (2017). SLA-aware and energyefficient dynamic overbooking in SDN-based cloud data centers. IEEE Transactions on Sustainable Computing, 2(2), pp.76-89.

[58] Pajila, P. B., \& Julie, E. G. (2019, February). Detection of DDoS Attack Using SDN in IoT: A Survey. In Intelligent Communication Technologies and Virtual Mobile Networks (pp. 438-452). Springer, Cham.

[59] Martínez, R., Mayoral, A., Vilalta, R., Casellas, R., Muñoz, R., Pachnicke, S., Szyrkowiec, T. and Autenrieth, A., (2017). Integrated SDN/NFV orchestration for the dynamic deployment of mobile virtual backhaul networks over a multilayer (packet/optical) aggregation infrastructure. Journal of Optical Communications and Networking, 9(2), pp.A135-A142.

[60] OpenStack Foundation. (2018). Open Source Software for Creating Private and Public Clouds. Retrieved from https://www.openstack.org/

[61] Mayoral, A., Munoz, R., Vilalta, R., Casellas, R., Martínez, R. and López, V., (2017). Need for a transport API in $5 \mathrm{G}$ for global orchestration of cloud and networks through a virtualized infrastructure manager and planner. IEEE/OSA Journal of Optical Communications and Networking, 9(1), pp.A55-A62.

[62] Fichera, S., Gharbaoui, M., Castoldi, P., Martini, B. and Manzalini, A., (2017), July. On experimenting 5G: Testbed set-up for SDN orchestration across network cloud and IoT domains. In Network Softwarization (NetSoft), 2017 IEEE Conference on (pp. 1-6). IEEE.

[63] Stallings, W. (2015). Foundations of modern networking: SDN, NFV, QoE, IoT, and Cloud. Addison-Wesley Professional.

[64] Calheiros, R.N., Ranjan, R., Beloglazov, A., De Rose, C.A. and Buyya, R., (2011). CloudSim: a toolkit for modeling and simulation of cloud computing environments and 
evaluation of resource provisioning algorithms. Software: Practice and experience, 41(1), pp.23-50.

[65] Badotra, S., \& Singh, J. (2017). A Review Paper on Software Defined Networking. International Journal of Advanced Research in Computer Science, 8(3).

[66] Kliazovich, D., Bouvry, P. and Khan, S.U., (2012). GreenCloud: a packet-level simulator of energy-aware cloud computing data centers. The Journal of Supercomputing, 62(3), pp.1263-1283.

[67] Network Simulator NS-2. Retrieved from http://www.isi.edu/nsnam/ns/

[68] Ahn, G. J., Gu, G., Hu, H., \& Shin, S. (2019, March). SDN-NFV security 2019 preface. In SDN-NFV 2019-Proceedings of the ACM International Workshop on Security in Software Defined Networks and Network Function Virtualization, co-located with CODASPY 2019 (p. III).

[69] Riley, G. F., \& Henderson, T. R. (2010). The ns-3 network simulator. In Modeling and tools for network simulation (pp. 15-34). Springer, Berlin, Heidelberg.

[70] Son, J., Dastjerdi, A.V., Calheiros, R.N., Ji, X., Yoon, Y. and Buyya, R., (2015), May. Cloudsimsdn: Modeling and simulation of software-defined cloud data centers. In Cluster, Cloud and Grid Computing (CCGrid), 2015 15th IEEE/ACM International Symposium on (pp. 475-484). IEEE.

[71] Teixeira, J., Antichi, G., Adami, D., Del Chiaro, A., Giordano, S. and Santos, A., (2013), October. Datacenter in a box: Test your sdn cloud-datacenter controller at home. In Software Defined Networks (EWSDN), 2013 Second European Workshop on (pp. 99-104). IEEE.

[72] Badotra, S. and Singh, J., (2017). Open Daylight as a Controller for Software Defined Networking. International Journal of Advanced Research in Computer Science, 8(5).

[73] Bhushan, K. and Gupta, B.B., (2017). Security challenges in cloud computing: state-ofart. International Journal of Big Data Intelligence, 4(2), pp.81-107.

[74] Bhushan, K., \& Gupta, B. B. (2019). Distributed denial of service (DDoS) attack mitigation in software defined network (SDN)-based cloud computing environment. Journal of Ambient Intelligence and Humanized Computing, 10(5), 1985-1997.

[75] Sezer, S., Scott-Hayward, S., Chouhan, P.K., Fraser, B., Lake, D., Finnegan, J., Viljoen, N., Miller, M. and Rao, N., (2013). Are we ready for SDN? Implementation challenges for software-defined networks. IEEE Communications Magazine, 51(7), pp.36-43.

[76] Jarschel, M., Oechsner, S., Schlosser, D., Pries, R., Goll, S. and Tran-Gia, P., (2011), September. Modeling and performance evaluation of an OpenFlow architecture. In Proceedings of the 23rd international teletraffic congress (pp. 1-7). International Teletraffic Congress.

[77] Pandya, B., Parmar, S., Saquib, Z. and Saxena, A., (2017), March. Framework for securing SDN southbound communication. In Innovations in Information, Embedded and Communication Systems (ICIIECS), 2017 International Conference on (pp. 1-5). IEEE.

[78] Yan, Q., Yu, F. R., Gong, Q., \& Li, J. (2015). Software-defined networking (SDN) and distributed denial of service (DDoS) attacks in cloud computing environments: A survey, some research issues, and challenges. IEEE Communications Surveys \& Tutorials, 18(1), 602-622.

[79] Sezer, S., Scott-Hayward, S., Chouhan, P.K., Fraser, B., Lake, D., Finnegan, J., Viljoen, N., Miller, M. and Rao, N.,(2013). Are we ready for SDN? Implementation challenges for software-defined networks. IEEE Communications Magazine, 51(7), pp.36-43.

[80] Yeganeh, S.H., Tootoonchian, A. and Ganjali, Y., (2013). On scalability of software-defined networking. IEEE Communications Magazine, 51(2), pp.136-141.

[81] Jantila, S. and Chaipah, K., (2016). A security analysis of a hybrid mechanism to defend DDoS attacks in SDN. Procedia Computer Science, 86, pp.437-440.

[82] Dargahi, T., Caponi, A., Ambrosin, M., Bianchi, G. and Conti, M., (2017). A survey on the security of stateful SDN data planes. IEEE Communications Surveys \& Tutorials, 19(3), pp.1701-1725.

[83] Wang, B., Zheng, Y., Lou, W. and Hou, Y.T., (2015). DDoS attack protection in the era of cloud computing and software-defined networking. Computer Networks, 81, pp.308-319. 
[84] Negru, C., Mocanu, M., Cristea, V., Sotiriadis, S. and Bessis, N., (2017). Analysis of power consumption in heterogeneous virtual machine environments. Soft Computing, 21(16), pp.4531-4542. 